\title{
Winds of change in East Asia
}

\author{
Michael J. Parnham
}

(C) Springer Basel AG 2011

With the increasing growth and development of the economies of countries in East Asia, it was inevitable that this would have repercussions on science publishing. Over the last decade, manuscript submissions to Inflammation Research from this part of the world have been increasing steadily. Currently, nearly $50 \%$ of published papers in the journal originate from countries in the region. East Asia has long been represented on the Editorial Board of Inflammation Research by Prof Makoto Katori. Dr Katori's association with the journal extends back to the days when the journal was called Agents and Actions and he has been an Associate Editor for over 25 years. He has accompanied and helped mould many of the changes we have experienced, as the journal metamorphosed to become one of the leading journals in the field of inflammation. (This year we achieved an impact factor of 2.04). Undoubtedly, Dr Katori's scientific reputation has facilitated the increasing use of the journal by researchers in East Asia. Dr Katori has now decided to relinquish his role as editor and to pass on the task to a younger scientist. The Editorial Board and publisher are very grateful for his conscientious and unstinting support over the many years and wish him all the very best.

We now welcome to the Editorial Board Dr Ikuo Morita, Professor and Vice-President, Tokyo Medical and Dental University. Dr Morita is also the official representative on the Editorial Board of the Japanese Society of Inflammation and Regeneration (JSIR). With this appointment the journal is, therefore, more tightly associated with the JSIR, a major member of the International Association of Inflammation Societies (IAIS), for which Inflammation Research is the official publication organ. Like Dr Katori before him, Dr Morita is a globally recognized researcher in the field of vascular biology and inflammation and will be the journal expert for this area, as well as representing Japan and East Asia on the Editorial Board. We are very pleased to be joined by Dr Morita and hope that this will be a further incentive to submission of high quality manuscripts from the East. 